\title{
Cross-cultural differences in concrete and abstract corporate social responsibility (CSR) campaigns: perceived message clarity and perceived CSR as mediators
}

Soojung Kim" ${ }^{1 *}$ and Jiyang Bae ${ }^{2}$

\begin{abstract}
Guided by Hofstede's (Culture's consequences: Comparing values, behaviors, institutions, and organizations across nations, 2001) cultural value of uncertainty avoidance, this study tests whether the effect of concrete vs. abstract CSR campaign messages on attitude toward the company and purchase intention varies by cultural difference in uncertainty avoidance and whether such effect is mediated by the perceived clarity of the message and perceived CSR. Lab experiments were performed in the U.S. and South Korea with American and Korean college students. Two-way ANOVA results revealed the relative advantage of concrete message on attitude toward the company and purchase intention among Koreans (vs. Americans) with high (vs. low) uncertainty avoidance. A series of bootstrap analysis testing multiple mediation models showed that the relative advantage of concrete message among Koreans was mediated by their perceived message clarity and perceived CSR in response to the concrete message. By identifying an international CSR campaign message strategy, the findings contribute to research on cross-cultural campaigns and CSR campaign effects.
\end{abstract}

Keywords: Corporate social responsibility, Uncertainty avoidance, Perceived message clarity, Perceived CSR, Cross-cultural campaigns

\section{Introduction}

According to a recent report from Cone Communications (2012), there is strong evidence of consumers' increasing focus on CSR activities: $83 \%$ of Americans wish brands and companies would support worthy causes, and $41 \%$ have purchased a product associated with a cause. This holds true for consumers with different cultural backgrounds. For instance, 64 and $63 \%$ of consumers in Asia and Latin America are respectively willing to pay more to purchase products or services from companies devoting themselves to CSR activities (Nielsen 2014). This global trend may be linked to companies' active participation in global CSR activities. According to Reputation Institute (2012), 100

\footnotetext{
* Correspondence: soojung.kim@und.edu

'Communication Program, University of North Dakota, O'Kelly Hall Room 332,

221 Centennial Drive Stop 7169, Grand Forks, ND 58202, USA

Full list of author information is available at the end of the article
}

reputable companies across 15 countries have spent 102.6 million dollars for implementing global CSR activities.

Despite companies' active participation in CSR activities, it remains unclear how they may effectively communicate CSR activities with consumers from different cultural backgrounds. CSR communication strategies that are adapted to consumers' cultural backgrounds could be essential (Ding 2006), especially when the message content and audience's message perception are tied to cultural values (e.g., Kim \& Johnson 2013). As individuals' cultural backgrounds are important consumer factors influencing campaign effects and effectiveness (de Mooij 2010), previous studies suggests the relative advantages of culturally adapted messages over standardized or culturally non-adapted messages (Han \& Shavitt 1994; Zhang \& Gelb 1996). 
Some CSR campaign messages include the information of a company's CSR activities in detail (e.g., type of CSR activities and donation amount), while others are not more image- or feeling-oriented (Olsen et al. 2003; Pracejus et al. 2003; Yoon 2015). Some researchers suggested that cultural values would play an important role in influencing the effects of CSR campaign messages with various degrees of CSR-related information presented in the messages (e.g., Bae 2011; Lee 2008).

With these situations as backdrops, this study tests the cultural differences of uncertainty avoidance level in the effects of concrete vs. abstract CSR messages on attitudes toward the company and purchase intention. In comparing different cultural groups, this study is based on a sample of Koreans and Americans. Koreans and Americans characterized as individuals with higher and lower uncertainty avoidance, respectively (de Mooij \& Hofstede 2010; Hofstede 2001; Hofstede et al. 2010).

In order to further understand the process whereby the effects of concrete vs. abstract CSR messages vary by the level of uncertainty avoidance, this study tests the mediating role of perceived message clarity and perceived CSR as mediators (Kim et al. 2010; Lichtenstein et al. 2004). In particular, this study adopts a multiple mediation approach to examine whether perceived message clarity and perceived CSR vary by cultural difference in response to the abstract vs. concrete messages, which may subsequently influence attitudes toward the company and purchase intention (Kim et al. 2010; Lin et al. 2011; Stanaland et al. 2011; Tian et al. 2011). In doing so, this study would contribute not only to the research stream on CSR communication research and campaign development, especially campaigns targeting different cultural or sub-cultural groups, but also to research on crosscultural campaign effects.

\section{Literature review and hypotheses Corporate social responsibility (CSR) activities and campaigns}

As a social obligation to represent a positive commitment to society, corporate social responsibility (CSR) is defined as the obligation "to pursue those policies, to make those decisions, or to follow those lines of action which are desirable in terms of the objectives and values of our society" (Bowen 1953, p. 6). Previous research indicates that CSR is effective in improving not only companies' financial performances (Orlitzky et al. 2003; Pava \& Krausz 1996), but also consumers' perceptions and beliefs about companies (Gonzalez 2007; Luo \& Bhattacharya 2006; Pfau et al. 2008; Sen et al. 2006). For instance, Pfau et al. (2008) found that CSR campaigns tended to enhance an organization's image, reputation, and credibility. Gonzalez (2007) also showed that CSR campaigns generated consumers' beliefs about an organization's contributions to the community and its trustworthiness. Thus, it is reasonable to expect that CSR advertising campaigns, which communicate an organization's socially responsible activities, would be likely to produce consumers' positive responses.

Cause-related marketing (CRM), a marketing form of CSR to communicate companies' donations to worthy causes, tends to generate similar positive outcomes (Nan \& Heo 2007; Ross et al. 1992; Smith \& Alcorn 1991; Webb \& Mohr 1998). For instance, consumers generally believe that CRM is a good way for companies to perform socially responsible behaviors (Ross et al. 1992). Consumers also tend to form positive attitudes toward the ad, company, brand, and product involved in a CRM campaign (Nan \& Heo 2007; Ross et al. 1992; Webb \& Mohr 1998). Furthermore, consumers are willing to purchase products from companies committed to CSR activities (Smith \& Alcorn 1991).

$\mathrm{Du}$, Bhattacharya, and Sen (2010) noted that message content and communication channels in CSR communications played an important role in affecting consumers' beliefs, attitudes, and behaviors. For instance, messages communicating CSR activities that are congruent (vs. incongruent) with an organization's characteristics (Menon \& Kahn 2003; Sen \& Bhattacharya 2001) and highlighting an organization's commitment to CSR activities (e.g., the amount of input) (Du et al. 2010; Dwyer et al. 1987) have been found to be effective. The following section discusses one of the CSR message strategies, namely, concrete vs. abstract message strategy.

Concrete vs. Abstract message strategy in CSR advertising campaign effects

Although CSR campaigns generally produce consumers' favorable responses (Gonzalez 2007; Pfau et al. 2008), previous research has not documented definitive answers to a companies' concern. The concern is related to the degree to which companies need to communicate CSR activities in detail. In the absence of the answer, some companies create CSR campaigns including specific facts (e.g., donation amount and the type of CSR activities) based on concrete terms and expressions, while other companies implement CSR campaigns using abstract expressions (Olsen et al. 2003; Pracejus et al. 2003).

The concrete message strategy is characterized as the use of specific information, terms, and 
expressions in messages so that audiences can easily understand and process the message (Hitchon et al. 1994; Liang \& Cherian 2010). In contrast, the abstract message strategy is characterized as the use of abstract terms and expressions (e.g., hope and happiness) in messages and, thus, audiences do not receive detailed information. Applying this concrete vs. abstract message strategy to the CSR advertising campaign context, consumers exposed to a concrete CSR campaign message could process information embedded in the message more easily than those exposed to an abstract CSR message.

Some studies reported that concrete advertising messages were more effective (Atkin et al. 2008; Hitchon et al. 1994; Ketelaar et al. 2010; Rossiter \& Percy 1980), whereas other studies found that abstract messages were more effective (Eisenberg 1984; Ha \& Hoch 1989; Hoch \& Ha 1986; McQuarrie \& Mick 2003). For example, Hitchon et al. (1994) showed that music video ads with a lower level of abstractness produced more favorable attitudes toward the ad and brand. Ketelaar et al. (2010) also found that consumers exposed to traditional ads were more likely to form positive attitude toward the ad than they do with open ads, which did not guide to specific information. In contrast, Ha and Hoch (1989) showed that consumers were more likely to be persuaded by ads with abstract components.

\section{The cultural value of uncertainty avoidance}

The cultural dimension of uncertainty avoidance (de Mooij \& Hofstede 2010; Hofstede 2001; Hofstede et al. 2010; House et al. 2010) can serve as a useful theoretical framework for explaining individuals' different responses to concrete vs. abstract CSR campaign messages. This is because different values held by individuals with different cultural backgrounds are likely to affect their patterns of message processing (Nisbett 2003; Nisbett \& Masuda 2003).

Uncertainty avoidance is defined as "the extent to which people feel threatened by uncertainty and ambiguity and try to avoid these situations" (de Mooij \& Hofstede 2010, p. 89). Individuals with a strong level of uncertainty avoidance are reluctant to accept changes and innovation (Yaveroglu \& Donthu 2002; Yeniurt \& Townsend 2003) and are more likely to establish detailed practices and social norms (Javidan et al. 2006). In contrast, individuals with a low level of uncertainty avoidance are willing to accept changes and take unknown risks (Yaveroglu \& Donthu 2002; Yeniurt \& Townsend 2003) and tend to prefer simple processes in the work situations (Javidan et al. 2006). Countries such as Japan, South Korea, and Greece are considered as high uncertainty avoidance societies, whereas countries such as the United States and Great Britain are considered as low uncertainty avoidance societies (Hofstede 2001).

The differences in the level of uncertainty avoidance among individuals from various cultural backgrounds are observed in a wide range of contexts and forms. Particularly, trust in other people and organizations and preference for clarity in consumer behaviors and organizational practices are relevant to this study. Given that trust can be considered as an individual's openness to take risk in a relationship (Schoorman et al. 2007), individuals with high uncertainty avoidance do not easily trust other people (Hofstede 2001). In contrast, individuals with low uncertainty avoidance tend to believe that most people can be trusted (Hofstede 2001). Similarly, Schoorman et al. (2007) found that people with high uncertainty avoidance were less likely to trust in for-profit companies than those with low uncertainty avoidance.

Individuals with high uncertainty avoidance are more likely to have a stronger need for clarity in consumer behaviors and organizational practices (Adler 1997; Lynn et al. 1993; Newman \& Nollen 1996). In particular, people with high uncertainty avoidance were less likely to engage in nonobligatory consumer behaviors (e.g., tipping) (Lynn et al. 1993). Newman and Nollen (1996) found that the clarity of management practices produced high work-unit performances among individuals with high uncertainty avoidance.

\section{The role of uncertainty avoidance in affecting the concrete vs. abstract message effects}

Considering the suggested connection between individuals' level of uncertainty avoidance and their beliefs and behaviors, the effects of concrete vs. abstract CSR messages may vary by individuals' level of uncertainty avoidance. Particularly, it is expected that individuals with a high level of uncertainty avoidance would respond to the concrete (vs. abstract) CSR campaigns more positively, whereas individuals with a low level of uncertainty avoidance would not be likely to respond to the concrete and abstract CSR campaigns differently.

Previous empirical studies found that advertising messages congruent with the target consumers' uncertainty avoidance were more persuasive (Garcia \& Yang 2006; Reardon et al. 2006). For instance, Garcia and Yang (2006) found that consumers with high uncertainty avoidance generated more favorable attitude toward the mild sex-appeal ad, whereas consumers with low uncertainty avoidance generated more favorable attitude toward the strong sex-appeal ad. This is because sex-appeal ads are often considered 
controversial and challenging in terms of the traditional ethical standard. Furthermore, Reardon et al. (2006) demonstrated that adolescents with high uncertainty avoidance responded more favorably to the negative (vs. positive) anti-smoking ad message, resulting from the fact that they were more motivated to avoid taking risks.

A few studies have been conducted to test the role of uncertainty avoidance in influencing the effects of concrete vs. abstract advertising messages. Particularly, Liang and Cherian (Liang \& Cherian 2010) tested the effects of concrete vs. abstract advertising messages by comparing Chinese consumers of high uncertainty avoidance with Americans consumers of low uncertainty avoidance. They found Chinese consumers who were more sensitive to their traditional values had more favorable attitude toward the ad with concrete words and ad contexts than with abstract words and no expressions. In contrast, American consumers who were less sensitive to others challenging their traditions did not show different levels of attitude toward the ad in response to concrete and abstract ad messages.

Applying a study by Liang and Cherian (Liang \& Cherian 2010) to this study's context, for individuals with a high level of uncertainty avoidance, a straightforward CSR message having specific information would be evaluated more positively. On the other hand, an abstract CSR message without clear information would be evaluated negatively. For individuals with a low level of uncertainty avoidance, two message conditions would not be evaluated differently. Thus, the following two hypotheses are posed:

Hypothesis 1: The concrete (vs. abstract) CSR message will produce more positive attitude toward the company for Koreans. However, such effects will not be observed for Americans.

Hypothesis 2: The concrete (vs. abstract) CSR message will produce greater purchase intention for Koreans. However, such effects will not be observed for Americans.

\section{Perceived message clarity and perceived CSR as mediators}

Perceived message clarity and perceived CSR may provide an explanation for why the positive effects of the concrete CSR message would be more prominent for some consumers. First, perceived message clarity is characterized as the extent to which audiences perceive media messages as clear and understandable without ambiguity or noise (Darley \& Smith 1995; Kim 2006; Kim et al. 2010; Yalch \& Elmore-Yalch 1984).

Research indicates that perceived message clarity is an outcome of concrete messages (Yalch \& Elmore-Yalch 1984) and a predictor of consumers' positive responses to such messages (Kim et al. 2010). More specifically, Yalch and Elmore-Yalch (Yalch \& Elmore-Yalch 1984) found that the message with a quantitative body copy, defined as a message with more clear evidence, generated a higher level of perceived message clarity than the non-quantitative message. Moreover, Kim and his colleagues (Kim 2006; Kim et al. 2010) considered message clarity one of the creative strategies and demonstrated that message clarity was a significant positive predictor of attitudes toward the ad and brand.

Perceived CSR is characterized by individuals' perceptions of a company incorporating charitable activities into its business (Drumwright \& Murphy 2001; Hess et al. 2002; Lichtenstein et al. 2004). Research indicates that perceived CSR is a response to CSR campaign messages (Lin 2005) and the antecedent of consumers' positive responses to CSR activities (Lin et al. 2011; Stanaland et al. 2011; Tian et al. 2011). More specifically, Tian et al. (2011) showed perceived CSR was a significant positive predictor of attitudes toward the company and purchase intentions. Similarly, Lin et al. (2011) documented that perceived CSR led consumers to trust the company, which subsequently generated greater purchase intentions. Additionally, Stanaland et al. (2011) found that perceived CSR positively influenced perceived corporate reputation, trust in the company, and consumer loyalty.

Taken together, perceived message clarity and perceived CSR are expected to mediate different responses to concrete CSR messages among individuals with high vs. low uncertainty avoidance (Kim 2006; Kim et al. 2010; Lin et al. 2011; Stanaland et al. 2011; Tian et al. 2011; Yalch \& Elmore-Yalch 1984). In other words, individuals with high uncertainty avoidance, compared to those with low uncertainty avoidance, would perceive the CSR campaign with concrete message components as more clear and understandable and perceive the company as actively incorporating charitable activities into its business. Those perceptions would subsequently result in their more positive attitudes toward the company and higher purchase intention. Thus, the following two mediation hypotheses are posed:

Hypothesis 3: The concrete message will generate higher perceived message clarity, which will have a positive effect on (a) attitude toward the company and (b) purchase intention for Koreans, but not for Americans. 
Hypothesis 4: The concrete message will generate higher perceived CSR, which will have a positive effect on (a) attitude toward the company and (b) purchase intention for Koreans, but not for Americans.

\section{Method}

A two message condition (concrete vs. abstract) by two cultural group (Koreans vs. Americans) factorial design was used. The concrete message condition included the specific information of a fictitious telecommunications company's CSR activity, habitat movement, whereas the abstract message did not provide any specific information about the company's CSR activity, but included abstract terms (e.g., happiness) only. Detailed descriptions about stimuli is discussed below.

This study tested the effects of concrete vs. abstract messages promoting a company's CSR activity based on participants from Korea and the U.S. Korea is considered one of the most uncertainty avoiding countries in the world, whereas the U.S. is considered a relatively uncertainty accepting country (Hofstede 2001; Hofstede et al. 2010).

\section{Sample}

A total of 90 American participants were recruited from undergraduate courses in a large Midwestern university in the U.S., and a total of 110 Korean participants were recruited from undergraduate courses at a large private university in Daegu, South Korea. The participating students received extra credit points in exchange for their voluntary participation.

The average age of the participants in the sample ranged from 19 to 33 , and the mean age was 21.93 ( $S D$ $=1.87$ ). In addition, $56 \%$ of the participants were female. In terms of Korean participants, $56 \%$ were female, and their age ranged from 19 to $33(M=22.23, S D=2.03)$. In terms of American participants, $57 \%$ were female, and their age ranged from 19 to $25(M=21.55, S D=1.55)$. Most of the participants were Caucasians (79 \%), followed by Asians/Asian Americans (11\%), others or mixed race (6\%), African-Americans (2\%), and Hispanics (2\%).

\section{Stimuli}

In this study, we created two versions of print ad promoting a company's CSR activity. To avoid priming any existing attitudes toward the company or business-specific stereotypes, a fictitious telecommunications company, Young Telecommunications, was used. Telecommunication companies have been often used in research on CSR campaign effects (e.g., Kim 2011). The habitat movement was used as the company's CSR activity because it is one of the most widely used CSR activities worldwide (Habitat for $\mathrm{Hu}$ manity 2013).

As described earlier, the conceptualization of the concrete (vs. abstract) condition in this study's context was defined the amount of specific information presented in the message. Based on Hitchon et al. (1994), the concrete message with detailed information is considered having enough concrete words and contexts for message recipients to avoid multiple interpretations and have a clear understanding of the message. On the contrary, the abstract message without detailed information is considered having many abstract words and, consequently, message recipients would be less likely to understand the message clearly.

Based on this conceptualization, both conditions read identical headline and sub-headline: "We will deliver hope to places in need and step up for the happiness of global citizens. Young Telecommunications is creating a world with dreams and a future through the habitat movement." In the following, the concrete message condition provided detailed information in the body copy such that Young Telecommunications' habitat movement in Southeast Asia has contributed to addressing severe housing problems, whereas the abstract message condition did not provide any specific information about this habitat movement. At the end of the body copy both conditions read an identical message describing the role of the habitat movement in addressing residential problems (see Appendix).

\section{Procedure}

The experiments were conducted in experimental labs in Korea and the U.S. Participants from each cultural group were randomly assigned to one of the two message conditions. There were 55 Koreans and 45 Americans in the concrete message condition, and there were 55 Koreans and 45 Americans in the abstract message condition. They were asked to view a printed version of advertisement and were asked to complete a questionnaire, which included questions about their responses to the message.

\section{Measures}

\section{Attitudes toward the company}

Participants were asked to indicate their attitudes toward the company using three 7-point semantic differential items: "bad-good," "unfavorable-favorable," and "negative-positive" (MacKenzie et al. 1986). The inter-item consistency for attitudes toward the company was acceptable, and the responses were averaged across the three items (Total: Cronbach's $\alpha=.93, M=4.96, S D=$ 1.11; Korea: Cronbach's $\alpha=.91, M=4.75, \quad S D=1.10$; U.S.: Cronbach's $\alpha=.94, M=5.21, S D=1.08$ ). 


\section{Purchase intention}

Purchase intention was measured by asking participants' agreement to the two measurement items: "It is likely that I will buy a Young Telecommunication's product in the near future" and "I intend to buy a Young Telecommunication's product in the near future" (Capella et al. 2010). The inter-item consistency for purchase intention was acceptable, and the responses were also averaged across the two items (Total: Pearson's $r=.79, M=3.46$, $S D=1.27$; Korea: Pearson's $r=.79, M=3.84, S D=1.23$; U.S.: Pearson's $r=.80, M=2.98, S D=1.16)$.

\section{Perceived message clarity}

Perceived message clarity was measured by asking participants to indicate the extent to which they believe the ad is "not easy to understand-easy to understand," "not immediately understandable-immediately understandable," "unclear-clear," and "not concise-concise" (Kim et al. 2010). The inter-item consistency was acceptable, and the responses were averaged across the four items (Total: Cronbach's $\alpha=.88, M=4.11, S D=1.40$; Korea: Cronbach's $\alpha$ $=.89, M=3.90, S D=1.48$; U.S.: Cronbach's $\alpha=.86, M$ $=4.37, S D=1.26)$.

\section{Perceived CSR}

Perceived CSR was measured by asking participants' agreement to the four measurement items. The items included: "Young Telecommunications is committed to using a portion of its profits to help others;" "Young Telecommunications gives back to the communities in which it does business;" "Young Telecommunications integrates charitable contributions into its business activities;" and "Young Telecommunications is greatly involved in corporate giving" (Lichtenstein et al. 2004). The inter-item consistency was acceptable, and the responses were averaged across the four items (Total: Cronbach's $\alpha=.87, M=4.70, S D=.98$; Korea: Cronbach's $\alpha=.88, M=4.56, S D=1.10$; U.S.: Cronbach's $\alpha=.84, M=$ 4.87, $S D=.79$ ).

\section{Cultural group manipulation check}

The cultural group manipulation check items assessed whether participants hold different levels of uncertainty avoidance. Specifically, participants were asked to indicate their agreement to the following statements (Furrer et al. 2000): "High stress and subjective feeling of anxiety are frequent among people;" "Fear of ambiguous situations and of unfamiliar risks is normal;" "Uncertainty is a normal feature of life and each day is accepted as it comes (reverse-coded);" and "Emotions should not be shown (reverse-coded)." (Total: Cronbach's $\alpha=.70, M=5.34, S D=1.06$; Korea: Cronbach's $\alpha=.72, M=5.48, S D=1.10$; U.S.: Cronbach's $\alpha=.65, M=5.17, S D=.99)$.

\section{Message manipulation check}

The message manipulation check items assessed whether participants perceived that the advertising message is clear and understandable. Specifically, participants were asked to indicate their agreement to the following statements: "It is clear what the message the company would like to convey through the ad" and "It is easy to understand the message that the company would like to convey through the ad." The inter-item consistency was acceptable, and the responses were averaged across the two items (Total: Pearson's $r=.80, M=4.14, S D=1.43$; Korea: Pearson's $r=.81, M=3.93, S D=1.33$; U.S.: Pearson's $r=.78, M=4.40, S D=1.50)$.

\section{Results}

\section{Cultural group manipulation check}

Cultural group manipulation checks tested if Korean and American participants hold different levels of uncertainty avoidance. As expected, Korean participants $(M=$ 5.48) held significantly stronger uncertainty avoidance than American participants $(M=5.17)(F(1,198)=4.27$, $\left.p<.05, \eta^{2}=.02\right)$.

\section{Message manipulation check}

The results of manipulation check verified that the participants perceived the two advertising messages differently. Particularly, the concrete message (Total: $M=4.52, S D=$ 1.40; Korea: $M=4.25, S D=1.25$; US: $M=4.83, S D=1.43$ ), compared with the abstract message (Total: $M=3.77$, $S D=1.36$; Korea: $M=3.60, S D=1.34$; US: $M=3.97$, $S D=1.46)$, contained clear information about the company's CSR activity (Total: $t(198)=3.84, p<.01$; Korea: $t(108)=2.64, p<.01 ;$ US: $t(88)=2.85, p<.01)$.

\section{Interaction effects between message condition and cultural group \\ H1: interaction effect on attitude toward the company}

$\mathrm{H} 1$ predicted that the concrete message would produce more positive attitude toward the company for Koreans. Two-way ANOVA results revealed significant interaction between message condition and cultural group $\left(F(1,195)=5.62, p<.05, \eta^{2}=.03\right)$ (see Fig. 1). Additionally, significant main effects were found for message condition $\left(F(1,195)=9.38, p<.01, \eta^{2}=.05\right)$ and cultural group $\left(F(1,195)=9.30, p<.05, \eta^{2}=.05\right)$. The concrete (vs. abstract) message and Americans (vs. Koreans) showed higher attitude toward the company. As shown in Table 1, the results from planned contrast tests showed that Koreans showed significant higher mean scores of attitude toward the company after receiving the concrete message $(M=5.16)$ than the abstract message $(M=4.34)$. Americans also showed higher mean scores of attitude toward the company after receiving the concrete message $(M=5.26)$ than the 


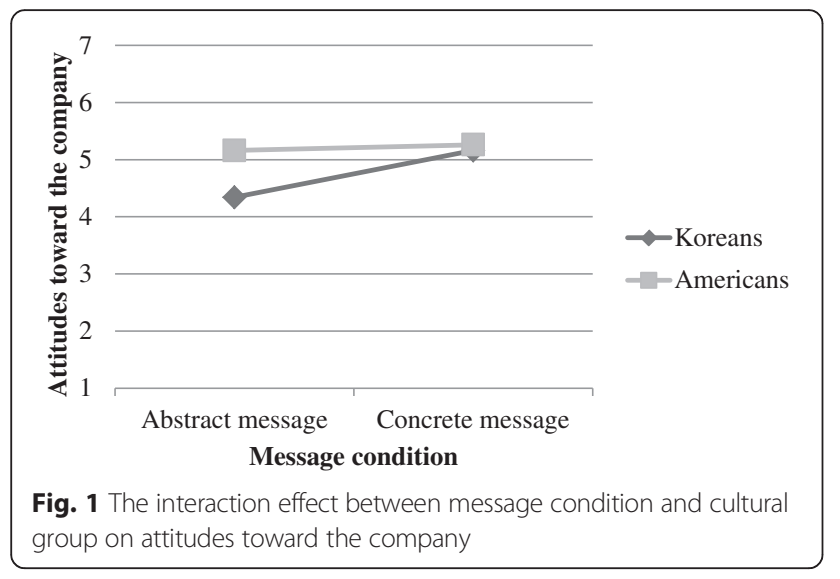

abstract message $(M=5.16)$. However, this mean difference was not statistically significant. The result indicates that the positive impact of the concrete message on attitude toward the company is greater for Koreans and that such effect is not observed for Americans. Thus, the result provides support for $\mathrm{H} 1$.

\section{H2: interaction effect on purchase intention}

$\mathrm{H} 2$ predicted that the concrete message would produce higher purchase intention for Koreans. Two-way ANOVA results revealed a significant interaction between message condition and cultural group $(F(1,196)=5.18$, $p<.05, \eta^{2}=.03$ ) (see Fig. 2). In addition, significant main effects were found for message condition $(F(1,196)=$ $\left.17.05, p<.01, \eta^{2}=.08\right)$ and cultural group $(F(1,196)=$ 28.39, $\left.p<.01, \eta^{2}=.13\right)$. The concrete (vs. abstract) message and Koreans (vs. Americans) showed higher purchase intention. As presented in Table 1, the results from planned contrast tests showed that Koreans

Table 1 Differences in attitudes toward the company and purchase intention

\begin{tabular}{lllllll}
\hline Dependent variables & & Mean & SD & $f$ & $p$ \\
\hline $\begin{array}{l}\text { Attitudes toward } \\
\text { the company }\end{array}$ & & & & & \\
Koreans & The concrete message & 5.16 & 1.08 & 17.11 & $.00^{*}$ \\
& The abstract message & 4.34 & .98 & & \\
Americans & The concrete message & 5.26 & .91 & .21 & .65 \\
& The abstract message & 5.16 & 1.23 & & \\
Purchase intentions & & & & & \\
Koreans & The concrete message & 4.36 & .85 & 23.48 & $.00^{*}$ \\
& The abstract message & 3.33 & 1.34 & & \\
Americans & The concrete message & 3.13 & 1.29 & 1.51 & .22 \\
& The abstract message & 2.83 & 1.01 & & \\
\hline
\end{tabular}

Note: ${ }^{*} p<.05$

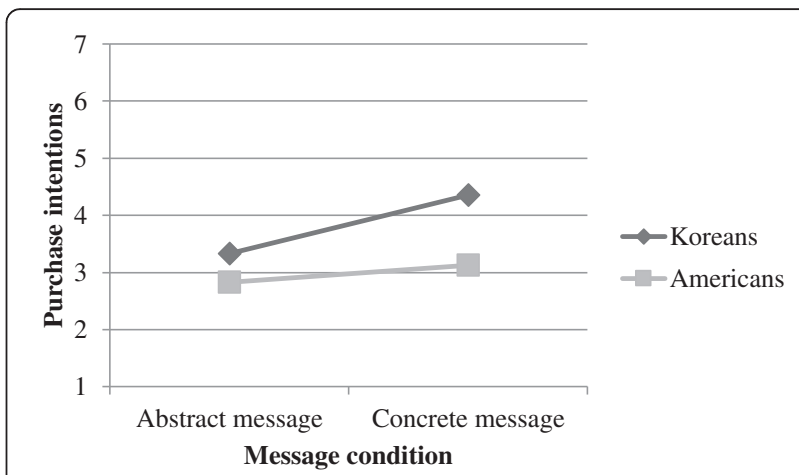

Fig. 2 The interaction effect between message condition and cultural group on purchase intentions

showed significant higher mean scores of purchase intention after receiving the concrete message $(M=$ 4.36) than the abstract message $(M=3.33)$. Americans also showed higher mean scores of purchase intention after receiving the concrete message $(M=3.13)$ than the abstract message $(M=2.83)$. However, this mean difference was found to be statistically non-significant. The result indicates that the positive impact of the concrete message on purchase intention is greater for Koreans and that such effect is not observed for Americans. Thus, H2 was supported.

\section{Mediation analyses}

A multiple mediation model was tested, separately for Americans and Koreans (Preacher \& Hayes 2008). As this study has two dependent variables, namely, attitude toward the company and purchase intention, it tested two multiple mediation models separately for Americans and Koreans. To test the significance of the indirect effects, this study performed a bootstrap analysis by using an SPSS macro (Mallinckrodt et al. 2006; Preacher \& Hayes 2008). In particular, the original sample of 90 Americans and 110 Koreans were used to generate a bootstrap sample of 90 and 110 participants with replacement. Testing the significant of indirect effects was based on these American and Korean bootstrap samples, and it was repeated with 5000 samples to obtain parameter estimates.

\section{H3: perceived message clarity as a mediator}

$\mathrm{H} 3$ predicted a significant mediation effect on (a) attitude toward the company and (b) purchase intention such that perceived message clarity would play a mediating role in explaining the effects of the positive effects of concrete (vs. abstract) message on (a) attitude toward the company and (b) purchase intention for Koreans. Figure 3 shows the results among 


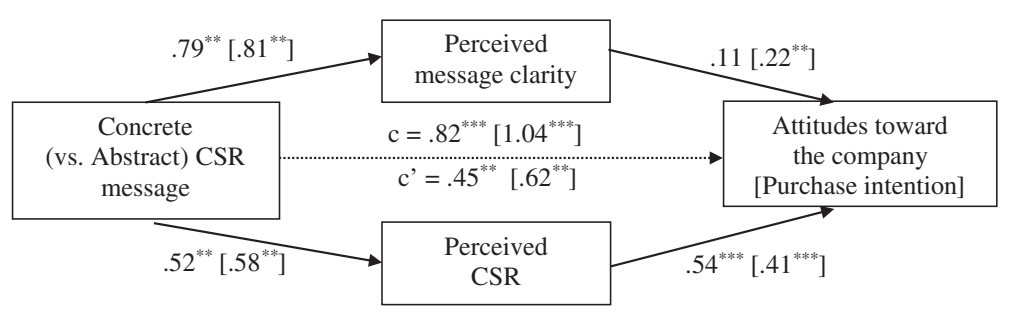

Fig. 3 A multiple mediation model for Koreans. Unstandardized regression coefficients from a bootstrap analysis are provided along the paths, with effects on attitude toward the company outside brackets and effects on purchase intention inside brackets. Note. $c$ is the total effect, which refers to the effect of concrete message on outcome variables without two mediators, and $c^{\prime}$ is the direct effect, which refers to the effect of concrete message on outcome variables after controlling for two mediators. ${ }^{* *} p<.01$. ${ }^{* * *} p<.001$

Koreans. Koreans perceived a concrete message to be more clear compared to an abstract message $(b=.79$, $p<.01)$. However, perceived message clarity did not have a significant impact on attitude toward the company $(\mathrm{b}=.11, p=.09)$. Additionally, Koreans perceived a concrete message to be more clear compared to an abstract message $(b=.81, p<.01)$, which in turn, generated higher purchase intention $(b=.22, p<.01)$. As shown in Table 2, the indirect effect of concrete (vs. abstract) message on purchase intention through perceived message clarity was significant, but not on attitude toward the company.

Figure 4 shows the results among Americans. The concrete message did not have a significant effect on perceived message clarity $(b=-.13, p=.62)$. Perceived message clarity did not have significant effects on (a) attitude toward the company $(\mathrm{b}=.09, p=.27)$ and (b) purchase intention $(\mathrm{b}=-.04, p=.67)$. Consequently, the indirect effects of concrete (vs. abstract) message on attitude toward the company and purchase intention through perceived message clarity were not significant (see Table 2).

The findings demonstrated that perceived message clarity played a mediating role in the effect of the concrete message on purchase intention, but not on attitude toward the company for Koreans. Perceived message clarity was not found be a significant mediator of the effects of the concrete message on attitude toward the company and purchase intention for Americans. Thus, H3a was not supported, whereas H3b was supported.

\section{H4: perceived CSR as a mediator}

$\mathrm{H} 4$ predicted a significant mediation effect on (a) attitude toward the company and (b) purchase intention such that perceived CSR would play a mediating role in explaining the effects of the positive effects of concrete (vs. abstract) message on (a) attitude toward the company and (b) purchase intention for Koreans.

Figure 3 shows the results among Koreans. Koreans showed higher perceived CSR in response to a concrete message, compared to an abstract message $(b=.52, p<.01)$, which in turn produced more positive attitude toward the company $(\mathrm{b}=.54, p<.01)$. Additionally, Koreans showed higher perceived CSR in response to a concrete message, compared to an abstract message $(\mathrm{b}=.58, p<.01)$, which in turn produced higher purchase intention $(\mathrm{b}=.41$, $p<.01)$ As shown in Table 2, the indirect effects of

Table 2 Indirect effects for Koreans and Americans

\begin{tabular}{|c|c|c|c|c|c|c|}
\hline \multirow[t]{2}{*}{ Paths } & \multicolumn{3}{|c|}{ Koreans } & \multicolumn{3}{|c|}{ Americans } \\
\hline & Beta & SE & $95 \% \mathrm{Cl}$ & Beta & SE & $95 \% \mathrm{Cl}$ \\
\hline \multicolumn{7}{|l|}{ H3: Perceived message clarity as a mediator } \\
\hline Concrete message $\rightarrow \gg$ Perceived message clarity $\rightarrow \gg A_{\text {company }}$ & .08 & .07 & -.01 to .26 & -.01 & .04 & -.14 to .03 \\
\hline Concrete message $-\gg$ Perceived message clarity $\rightarrow \gg \mathrm{PI}$ & .18 & .09 & .05 to .41 & .01 & .03 & -.03 to .13 \\
\hline \multicolumn{7}{|l|}{ H4: Perceived CSR as a mediator } \\
\hline Concrete message $\rightarrow \gg$ Perceived CSR $\rightarrow$ $A_{\text {company }}$ & .28 & .11 & .10 to .52 & .01 & .11 & -.20 to .25 \\
\hline Concrete message $\rightarrow \gg$ Perceived CSR $\rightarrow$ PI & .24 & .10 & .08 to .48 & .00 & .04 & -.07 to .11 \\
\hline
\end{tabular}

Note: $A_{\text {company }}$ Attitudes toward the company, $B /$ Purchase intention, $\mathrm{Cl}$ confidence intervals The confidence intervals containing zero indicate that the indirect effects are not significant 


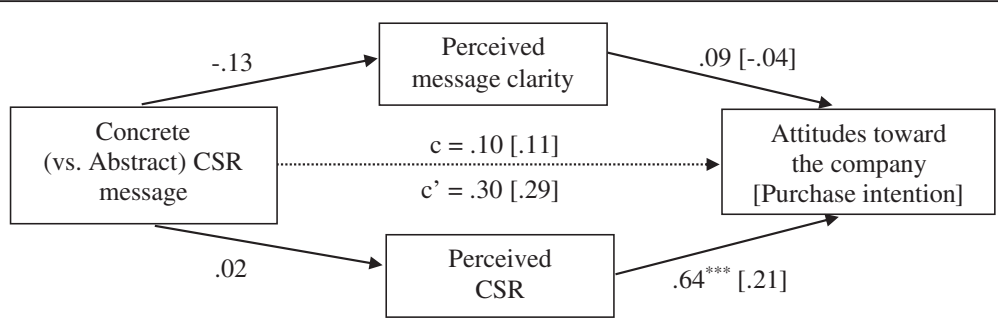

Fig. 4 A multiple mediation model for Americans. Unstandardized regression coefficients from a bootstrap analysis are provided along the paths, with effects on attitude toward the company outside brackets and effects on purchase intention inside brackets. Note. $c$ is the total effect, which refers to the effect of concrete message on outcome variables without two mediators, and $c^{\prime}$ is the direct effect, which refers to the effect of concrete message on outcome variables after controlling for two mediators. ${ }^{* *} p<.001$

concrete (vs. abstract) message on attitude toward the company and purchase intention through perceived CSR were significant.

Figure 4 shows the results among Americans. The concrete message did not have a significant effect on perceived CSR ( $b=.02, p=.92)$. Perceived CSR had a significant effect on attitude toward the company $(\mathrm{b}=.64$, $p<.01)$, but not on purchase intention $(\mathrm{b}=.21, p=.21)$. As shown in Table 2, the indirect effects of concrete (vs. abstract) message on attitude toward the company and purchase intention through perceived CSR were not significant.

The findings demonstrated that perceived CSR played a mediating role in the effects of the concrete message on attitude toward the company and purchase intention for Koreans, but not for Americans. Thus, both H4a and H4b were supported.

\section{Discussion}

In this study, we examined (1) the role of uncertainty avoidance in influencing the effects of concrete vs. abstract CSR messages on attitude toward the company and purchase intention and (2) the role of perceived message clarity and perceived CSR in mediating such interaction effects. We found the positive effects of concrete message on attitude toward the company and purchase intention were more prominent for Koreans with high uncertainty avoidance than for Americans with low uncertainty avoidance.

This study also found that Koreans' relatively more positive responses to the concrete (vs. abstract) message could be explained by different levels of perceptions regarding the CSR campaign message and the CSR activity between two countries. More specifically, Koreans showed more positive attitude toward the company in response to the concrete message than to the abstract message because the concrete message was more likely to lead them perceive that the company incorporated socially responsible activities into its business (i.e., perceived CSR). Additionally, Koreans showed greater purchase intention in response to the concrete message than to the abstract message because the concrete message was perceived to be more clear, and it contributed to generating higher perceived CSR.

This study contributes to the international advertising and public relations literature by applying the cultural dimension of uncertainty avoidance to the CSR campaign context. Unlike the cultural dimension of individualismcollectivism (Hornikx \& O'Keefe 2009) that has received much empirical research attention, the cultural dimension of uncertainty avoidance has been relatively the under-examined. Therefore, this study's findings offer empirical evidence that cultural differences in terms of the level of uncertainty avoidance is an important factor influencing CSR campaign outcomes.

Although Maio and Haddock (2007) noted cultural differences may function "as an enabler of persuasion but not as an elicitor of persuasion" (p. 578), little empirical research attention has been devoted to examining potential mediators to provide an explanation for why the effects of message characteristics vary by cultural difference (Taylor 2002; Taylor 2005). While prior research has examined perceived message clarity and perceived CSR in the context of advertising creativity (Kim et al. 2010) or treated it as one of communication outcomes (Lin et al. 2011; Stanaland et al. 2011; Tian et al. 2011; Yalch \& Elmore-Yalch 1984), this study tested it as a mediator that can explain for why there are cross-cultural differences in response to the concrete vs. abstract messages. Based on this study's finding, advertising practitioners are advised to create clear and easily understandable messages for cultural groups with high uncertainty avoidance in order to increase the likelihood of generating better communication outcomes.

In terms of two mediators, perceived message clarity mediated the effects of concrete (vs. abstract) 
message on purchase intention only, whereas perceived CSR mediated the effects of concrete (vs. abstract) message on attitude toward the company and purchase intention. The finding seems to suggest that perceived CSR could better explain Koreans' positive communication outcomes in response to the concrete message. In other words, Koreans' higher perception of message clarity in response to the concrete (vs. abstract) message did not lead to attitude toward the company.

Although this study showed relatively positive effects of the concrete (vs. abstract) message on attitude toward the company and purchase intention mediated by perceived message clarity and perceived CSR for Koreans, Americans did not show any significant differences in response to both the concrete and abstract messages. This finding for Americans might be explained by universally positive attitudes toward CSR activities and campaigns among consumers, regardless of the message content features (Gonzalez 2007; Nan \& Heo 2007). Consequently, this may have caused insufficient variability in scores for attitude toward the company and purchase intention for Americans.

This study also makes meaningful contributions to international advertising and public relations literature by using multiple mediation analyses (Preacher \& Hayes 2008). Previous research has been conducted to demonstrate the relative advantage of a match between what campaign messages adopt message strategies or executional techniques and what the message recipients considered them well-aligned with their cultural values (Garcia \& Yang 2006; Han \& Shavitt 1994; Reardon et al. 2006; Zhang \& Gelb 1996). Testing potential mediators in conjunction with the interaction between message strategies and audiences' cultural characteristics has been limited, however. Thus, this study addresses the gap in the literature by adopting multiple mediation analyses.

This study's findings offer useful practical implications for developing effective campaign strategies, particularly focusing on how to effectively communicate CSR activities. Communication practitioners implementing CSR or CRM campaigns across different cultural groups should carefully examine audience's cultural backgrounds and their impacts on individuals' message processing, and develop culturally adaptive messages. For instance, individuals with a high level of uncertainty avoidance are likely to purchase life insurances (Chui \& Kwok 2007). In case insurance companies try to communicate their CSR activities with their consumers, they are advised to include specific information in their CSR messages in order to maximize the marketerintended effects and effectiveness. In other words, this study contributes to developing message strategies for effective CSR campaigns by focusing on individuals' cultural values.

The multiple mediation approach also offers implications for communication practitioners. Mediators are considered more proximal outcomes of campaign messages than other outcomes, such as message recall, attitude toward the company, and purchase intention. Given that it is not always easy to directly change consumers' memory, attitudes, or purchase intentions through a single campaign message (Hornikx \& O'Keefe 2009), practitioners could develop message strategies aiming at changing proximal outcomes (i.e., mediators), instead of distal outcomes (e.g., recall, attitudes, and purchase behavior). For example, practitioners are advised to focus on developing message strategies that can produce favorable message perceptions or evaluations among individuals of strong Confucian values as a way to generate desirable communication outcomes (Kim et al. 2010).

\section{Limitations and suggestions for future research}

This study has some methodological limitations. Since this study used college students enrolled in Korean and American universities, which are not representative of Koreans and Americans. Consequently, the findings might not be generalizable to the general population of Koreans and Americans. Additionally, the experimental stimuli were created by the researchers, which may affect ecological validity. In order to address the methodological limitation of this experimental study, future researchers are encouraged to conduct survey research to examine a relationship between cultural values (e.g., uncertainty avoidance) and message preference with a representative sample (e.g., Bae \& Kim 2013).

Considering the study limitations and building on this study's findings, future researchers are encouraged to replicate this study in other contexts. For example, future researchers should consider replicating this study in the context of other corporate marketing communications, such as CRM, since different cultural groups have different responses to messages promoting a company's donations to worthy causes (Kim \& Johnson 2013; Lavack \& Kropp 2003). Additionally, given that $\mathrm{Du}$ et al. (2010) suggested that communication channels are likely to play an essential role in CSR communications, future researchers are encouraged to focus on the different media (e.g., television and social networking sites) in affecting the effects and effectiveness of CSR campaigns across countries. 


\section{Appendix}

We will deliver hope to places in need and step up for the happiness of global citizens

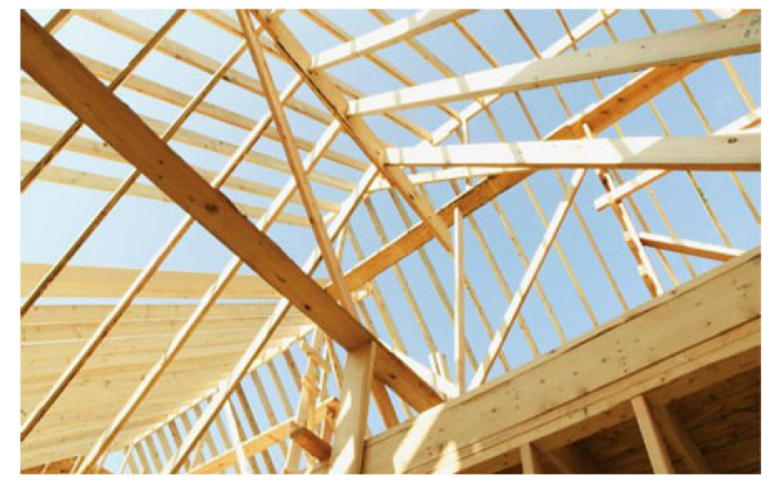

Young Telecommunications is creating a world with dreams and a future through the Habitat movement

We will strive to empathize the sufferings of local residents in developing countries and resolve residential problems based on our confidence that only we can do this.

Global Communication Leader

Young Telecommunications 


\section{We will deliver hope to places in need and step up for the happiness of global citizens}

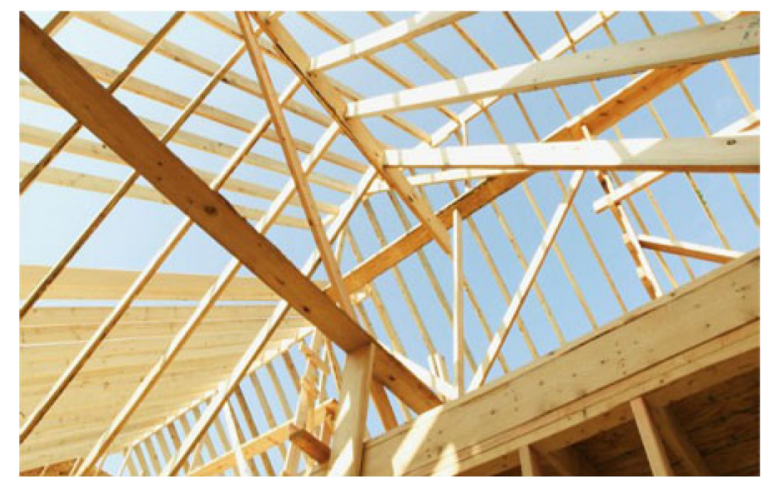

Young Telecommunications is creating a world with dreams and a future through the Habitat movement

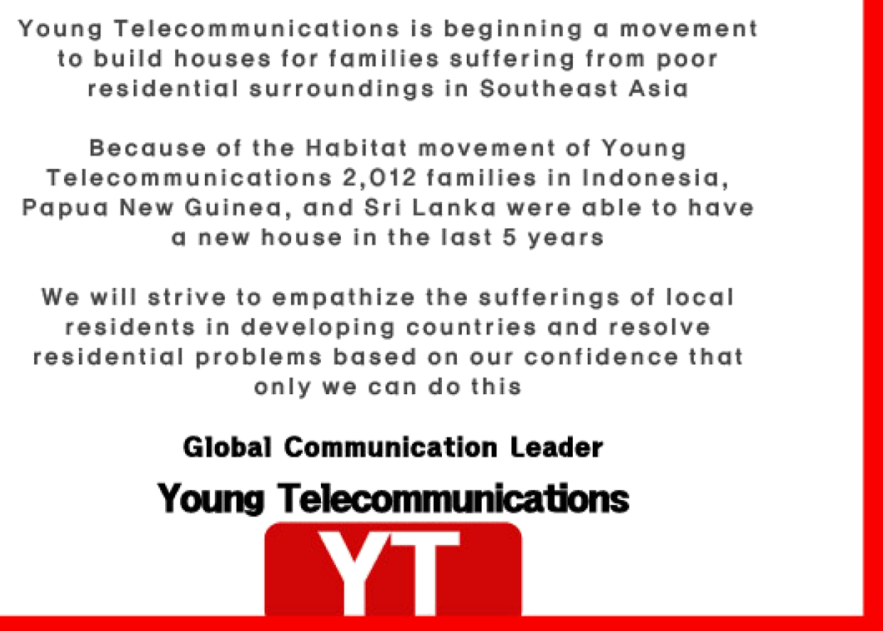

Fig. 6 The concrete message

\section{Abbreviations}

ANOVA, analysis of variance; CRM, cause-related marketing; CSR, corporate social responsibility; SPSS, statistical package for the social sciences

\section{Acknowledgments}

We thank two anonymous reviewers for their valuable comments.

\section{Funding}

There is no funding source for this study.

\section{Availability of data and materials}

The corresponding author will provide data supporting this study's findings upon request.

\section{Authors' contributions}

The first author serves as the corresponding author and played a leading role in collecting data and preparing and submitting the manuscript. The second author was involved in data collection. Both authors read and approved the final manuscript.

\section{Competing interests}

The authors declare that they have no competing interests.

\section{Author details}

${ }^{1}$ Communication Program, University of North Dakota, O'Kelly Hall Room 332, 221 Centennial Drive Stop 7169, Grand Forks, ND 58202, USA. ²Department of Communication, Chonnam National University, 77 Yongbongro, Bukgu, Gwangju 500-757, South Korea.

Received: 29 May 2016 Accepted: 14 July 2016 Published online: 02 August 2016

\section{References}

Adler, N. J. (1997). International dimensions of organizational behavior. Cincinnati: South-Western.

Atkin, J. L., McCardle, M., \& Newell, S. J. (2008). The role of advertiser motives in consumer evaluations of 'responsibility' messages from the alcohol industry. Journal of Marketing Communications, 14(4), 315-335. doi:10.1080/ 13527260802141447

Bae, J. (2011). The influence of the vagueness in CSR messages on public's CSR perception, attitude toward the company, and purchase intention: Focusing on the moderating effects of public's self-humbleness communication propensity and uncertainty avoidance propensity. Korean Journal of Journalism and Communication Studies, 55(1), 5-31. 
Bae, J., \& Kim, S. (2013). The influence of cultural aspects on public perception of the importance of CSR activity and purchase intention in Korea. Asian Journal of Communication, 23(1), 68-85. doi:10.1080/01292986.2012.725174

Bowen, H. R. (1953). Social responsibilities of the businessman. New York: Harper \& Row.

Capella, M. L., Hill, R. P., Rapp, J. M., \& Kees, J. (2010). The impact of violence against women in advertisements. Journal of Advertising, 39(4), 37-51. doi:10. 2753/JOA0091-3367390403

Chui, A. C., \& Kwok, C. C. Y. (2007). National culture and life insurance consumption. Journal of International Business Studies, 39(1), 88-101. doi:10. 1057/palgrave.jibs.8400316

Cone Communications (2012). Cone Cause Evolution Study. Boston.

Darley, W. K., \& Smith, R. E. (1995). Gender differences in information processing strategies: an empirical test of the selectivity model in advertising response. Journal of Advertising, 24(1), 41-56. doi:10.1080/ 00913367.1995.10673467

de Mooij, M. (2010). Global marketing and advertising: understanding cultural paradoxes. Thousand Oaks: Sage.

de Mooii, M., \& Hofstede, G. (2010). The Hofstede model: applications to global branding and advertising strategy and research. International Journal of Advertising, 29(1), 85-110. doi:10.2501/S026504870920104X

Ding, D. D. (2006). An indirect style in business communication. Journal of Business and Technical Communication, 20(1), 87-100. doi:10.1177/ 1050651905281051

Drumwright, M. E., \& Murphy, P. E. (2001). Corporate societal marketing. In P. N. Bloom \& G. Gundlach (Eds.), Handbook of marketing and society (pp. 162183). Thousand Oaks: Sage Publications.

Du, S., Bhattacharya, C. B., \& Sen, S. (2010). Maximizing business returns to corporate social responsibility (CSR): The role of CSR communication. International Journal of Management Reviews, 12(1), 8-19. doi:10.1111/j.14682370.2009.00276.x

Dwyer, F. R., Schurr, P. H., \& Oh, S. (1987). Developing buyer-seller relationships. The Journal of Marketing, 51(2), 11-27. doi:10.2307/1251126

Eisenberg, E. M. (1984). Ambiguity as strategy in organizational communication. Communication Monographs, 51, 227-242. doi:10.1080/03637758409390197

Furrer, O., Liu, B. S.-C., \& Sudharshan, D. (2000). The relationships between culture and service quality perceptions: Basis for cross-cultural market segmentation and resource allocation. Journal of Service Research, 2(4), 355-371. doi:10. $1177 / 109467050021004$

Garcia, E., \& Yang, K. C. C. (2006). Consumer responses to sexual appeals in crosscultural advertisements. Journal of International Consumer Marketing, 19(2), 29-52. doi:10.1300/J046v9n02.03

Gonzalez, C. M. (2007). The effect of doing good: An experimental analysis of the influence of corporate social responsibility initiatives on beliefs, attitudes, and behavioral intentions (Unpublished Master's thesis). Tampa: University of South Florida.

Ha, Y.-W., \& Hoch, S. J. (1989). Ambiguity, processing strategy, and advertisingevidence interactions. Journal of Consumer Research, 16(3), 354-360. doi:10. 1086/209221

Habitat for Humanity. (2013). Corporate and foundations involvement. Retrieved on June 30, 2016 from http://www.habitat.org/lac_eng/participate/ corporate_partners.aspx.

Han, S.-P., \& Shavitt, S. (1994). Persuasion and culture: advertising appeals in individualistic and collectivistic societies. Journal of Experimental Social Psychology, 30(4), 326-350. doi:10.1006/jesp.1994.1016

Hess, D., Rogovsky, N., \& Dunfee, T. W. (2002). The next wave of corporate community involvement: corporate social initiatives. California Management Review, 44(2), 110-125. doi:10.2307/41166125

Hitchon, J., Duckler, P., \& Thorson, E. (1994). Effects of ambiguity and complexity on consumer response to music video commercials. Journal of Broadcasting \& Electronic Media, 38(3), 289-306. doi:10.1080/08838159409364266

Hoch, S. J., \& Ha, Y.-W. (1986). Consumer learning: advertising and the ambiguity of product experience. Journal of Consumer Research, 13(2), 221-233. doi:10. $1086 / 209062$

Hofstede, G. (2001). Culture's consequences: comparing values, behaviors, institutions, and organizations across nations (2nd ed.). London, United Kingdom: Sage Publications.

Hofstede, G., Hofstede, G. J., \& Minkov, M. (2010). Cultures and organizations: software of the mind. New York, NY: McGraw Hill.

Hornikx, J., \& O'Keefe, D. J. (2009). Adapting consumer advertising appeals to cultural values. Communication Yearbook, 33, 38-71.
House, R. J., Quigley, N. R., \& de Luque, M. S. (2010). Insights from Project GLOBE. International Journal of Advertising, 29(1), 111-139. doi:10.2501/ S0265048709201051

Javidan, M., Dorfman, P. W., De Luque, M. S., \& House, R. J. (2006). In the eye of the beholder: cross-cultural lessons in leadership from project GLOBE. Academy of Management Perspectives, 20(1), 67-90. doi:10.5465/AMP.2006. 19873410

Ketelaar, P. E., van Gisbergen, M. S., Bosman, J. A. M., \& Beentjes, H. (2010). The effects of openness on attitude toward the ad, attitude toward the brand, and brand beliefs in Dutch magazine ads. Journal of Current Issues \& Research in Advertising, 32(2), 71-85.

Kim, B. H. (2006). A study on development of a scale to measure advertising creativity (Unpublished doctoral dissertation). Ansan, Korea: Hanyang University.

Kim, S. (2011). Transferring effects of CSR strategy on consumer responses: the synergistic model of corporate communication strategy. Journal of Public Relations Research, 23(2), 218-241. doi:10.1080/1062726X.2011.555647

Kim, J.E., \& Johnson, K. K. P. (2013). The impact of moral emotions on causerelated marketing campaigns: a cross-cultural examination. Journal of Business Ethics, 112(1), 79-90. doi:10.1007/s10551-012-1233-6

Kim, B. H., Han, S., \& Yoon, S. (2010). Advertising creativity in Korea. Journal of Advertising, 39(2), 93-108. doi:10.2753/JOA0091-3367390207

Lavack, A. M., \& Kropp, F. (2003). A cross-cultural comparison of consumer attitudes toward cause-related marketing. Social Marketing Quarterly, 9(2), 3-17. doi:10.1080/15245000309103

Lee, H. (2008). The differences of ambiguous advertising message effect caused by uncertainty avoidance. The Korean Journal of Advertising, 19(3), 135-155.

Liang, B., \& Cherian, J. (2010). Cross-cultural differences in the effects of abstract and concrete thinking on imagery generation and ad persuasion. Journal of International Consumer Marketing, 22(2), 187-198. doi:10.1080/ 08961530903476253

Lichtenstein, D. R., Drumwright, M. E., \& Braig, B. M. (2004). The effect of corporate social responsibility on customer donations to corporatesupported nonprofits. Journal of Marketing, 16-32. doi:10.1509/jmkg.68.4.16. 42726

Lin, S. Y. (2005). A public relations campaign of corporate social responsibility: A test of a cognitive processing model of a CSR message (Unpublished master's thesis). Gainesville, FL: University of Florida.

Lin, C. P., Chen, S. C., Chiu, C. K., \& Lee, W. Y. (2011). Understanding purchase intention during product-harm crises: Moderating effects of perceived corporate ability and corporate social responsibility. Journal of Business Ethics, 102(3), 455-471. doi:10.1007/s10551-011-0824-y

Luo, X., \& Bhattacharya, C. B. (2006). Corporate social responsibility, customer satisfaction, and market value. Journal of Marketing, 70(4), 1-18. doi:10.1509/ jmkg.70.4.1

Lynn, M., Zinkhan, G. M., \& Harris, J. (1993). Consumer tipping: a cross-country study. Journal of Consumer Research, 20(3), 478-488. doi:10.1086/209363

MacKenzie, S. B., Lutz, R. J., \& Belch, G. E. (1986). The role of attitude toward the ad as a mediator of advertising effectiveness: a test of competing explanations. Journal of Marketing Research, 23(2), 130-143. doi:10.2307/ 3151660

Maio, G. R., \& Haddock, G. (2007). Attitude change. In A. Kruglanski \& E. T. Higgins (Eds.), Social psychology: handbook of basic principles (pp. 565-586). New York, NY: The Guildford Press.

Mallinckrodt, B., Abraham, W. T., Wei, M., \& Russell, D. W. (2006). Advances in testing the statistical significance of mediation effects. Journal of Counseling Psychology, 53(3), 372-378. doi:10.1037/0022-0167.53.3.372

McQuarrie, E. F., \& Mick, D. G. (2003). Visual and verbal rhetorical figures under directed processing versus incidental exposure to advertising. Journal of Consumer Research, 29(4), 579-587.

Menon, S., \& Kahn, B. E. (2003). Corporate sponsorships of philanthropic activities: when do they impact perception of sponsor brand? Journal of Consumer Psychology, 13(3), 316-327. doi:10.1207/S15327663JCP1303_12

Nan, X., \& Heo, K. (2007). Consumer responses to corporate social responsibility (CSR) initiatives: examining the role of brand-cause fit in cause-related marketing. Journal of Advertising, 36(2), 63-74. doi:10.2753/JOA00913367360204

Newman, K. L., \& Nollen, S. D. (1996). Culture and congruence: the fit between management practices and national culture. Journal of International Business Studies, 27(4), 753-779. doi:10.1057/palgrave.jibs.8490152 
Nielsen. (2014). Global consumers are willing to put their money where their heart is when it comes to goods and services from companies committed to social responsibility. Retrieved on June 30, 2016 from: http://www.nielsen.com/us/ en/press-room/2014/global-consumers-are-willing-to-put-their-money-wheretheir-heart-is.html.

Nisbett, R. E. (2003). The geography of thought: how Asians and westerners think differently - and why. New York: Free Press.

Nisbett, R. E., \& Masuda, T. (2003). Culture and point of view. Proceedings of the National Academy of Sciences of the United States of America, 100(19), 1116311170. doi:10.1073/pnas.1934527100

Olsen, G. D., Pracejus, J. W., \& Brown, N. R. (2003). When profit equals price: consumer confusion about donation amounts in cause-related marketing Journal of Public Policy \& Marketing, 22(2), 170-180. doi:10.1509/jppm.22.2.170. 17641

Orlitzky, M., Schmidt, F. L., \& Rynes, S. L. (2003). Corporate social and financial performance: a meta-analysis. Organization Studies, 24(3), 403-441. doi:10. 1177/0170840603024003910

Pava, M., \& Krausz, J. (1996). Corporate social responsibility and financial performance: the paradox of social cost. Westport, CR: Quorum Books.

Pfau, M., Haigh, M. M., Sims, J., \& Wigley, S. (2008). The influence of corporate social responsibility campaigns on public opinion. Corporate Reputation Review, 11(2), 145-154. doi:10.1057/crr.2008.14

Pracejus, J. W., Olsen, G. D., \& Brown, N. R. (2003). On the prevalence and impact of vague quantifiers in the advertising of cause-related marketing (CRM). Journal of Advertising, 32(4), 19-28. doi:10.1080/00913367.2003. 10639146

Preacher, K. J., \& Hayes, A. F. (2008). Asymptotic and resampling strategies for assessing and comparing indirect effects in multiple mediator models. Behavior Research Methods, 40(3), 879-891. doi:10.3758/BRM.40.3.879

Reardon, J., Miller, C., Foubert, B., Vida, I., \& Rybina, L. (2006). Antismoking messages for the international teenage segment: the effectiveness of message valence and intensity across different cultures. Journal of International Marketing, 14(3), 115-138. doi:10.1509/jimk.14.3.115

Reputation Institute. (2012). The 2012 global RepTrak 100: Results and report. Retrieved on June 30, 2016 from: http://www.rankingthebrands.com/PDF/ 2012\%20RepTrak\%20100-Global_Report,\%20Reputation\%20Institute.pdf.

Ross, J. K., III, Patterson, L. T., \& Stutts, M. A. (1992). Consumer perceptions of organizations that use cause-related marketing. Journal of the Academy of Marketing Science, 20(1), 93-97. doi:10.1007/BF02723480

Rossiter, J., \& Percy, L. (1980). Advertising and promotion management. New York, NY: McGraw Hill.

Schoorman, F. D., Mayer, R. C., \& Davis, J. H. (2007). An integrative model of organizational trust: past, present, and future. Academy of Management Review, 32(2), 344-354. doi:10.5465/AMR.2007.24348410

Sen, S., \& Bhattacharya, C. B. (2001). Does doing good always lead to doing better? Consumer reactions to corporate social responsibility. Journal of Marketing Research, 38(2), 225-243. doi:10.1509/jmkr.38.2.225.18838

Sen, S., Bhattacharya, C. B., \& Korschun, D. (2006). The role of corporate social responsibility in strengthening multiple stakeholder relationships: a field experiment. Journal of the Academy of Marketing Science, 34(2), 158-166. doi: $10.1177 / 0092070305284978$

Smith, S. M., \& Alcorn, D. S. (1991). Cause marketing: a new direction in the marketing of corporate responsibility. Journal of Services Marketing, 5(4), 21-37.

Stanaland, A. J., Lwin, M. O., \& Murphy, P. E. (2011). Consumer perceptions of the antecedents and consequences of corporate social responsibility. Journal of Business Ethics, 102(1), 47-55. doi:10.1007/s10551-011-0904-z

Taylor, C. R. (2002). What is wrong with international advertising research? Journal of Advertising Research, 42(6), 48-54.

Taylor, C. R. (2005). Moving international advertising research forward: a new research agenda. Journal of Advertising, 34(1), 7-16. doi:10.1080/00913367. 2005.10639187

Tian, Z., Wang, R., \& Yang, W. (2011). Consumer responses to corporate social responsibility (CSR) in China. Journal of business ethics, 101(2), 197-212. doi: 10.1007/s10551-010-0716-6

Webb, D. J., \& Mohr, L. A. (1998). A typology of consumer responses to causerelated marketing: from skeptics to socially concerned. Journal of Public Policy \& Marketing, 17(2), 226-238

Yalch, R. F., \& Elmore-Yalch, R. (1984). The effect of numbers on the route to persuasion. Journal of Consumer Research, 11(1), 522-527. doi:10.1086/208988
Yaveroglu, I. S., \& Donthu, N. (2002). Cultural influences on the diffusion of new products. Journal of International Consumer Marketing, 14(4), 49-63. doi:10. 1300/J046v14n04_04

Yeniurt, S., \& Townsend, J. D. (2003). Does culture explain acceptance of new products in a country? International Marketing Review, 20(4), 377-396. doi:10. 1108/02651330310485153

Yoon, D. (2015). Corporate social responsibility (CSR) advertising and consumer responses in the lodging industry: Functions of green marketing motive and appeal type (Unpublished doctoral dissertation). University of Tennessee, Knoxville, TN. Retrieved on June 30, 2016 from: http://trace.tennessee.edu/ utk_graddiss/3487

Zhang, Y., \& Gelb, B. D. (1996). Matching advertising appeals to culture: the influence of products' use conditions. Journal of Advertising, 25(3), 29-46. doi: 10.1080/00913367.1996.10673505

\section{Submit your manuscript to a SpringerOpen ${ }^{\circ}$ journal and benefit from:}

- Convenient online submission

- Rigorous peer review

- Immediate publication on acceptance

- Open access: articles freely available online

- High visibility within the field

- Retaining the copyright to your article

Submit your next manuscript at springeropen.com 